\title{
Did you witness demonic possession? A response time analysis of the relationship between event plausibility and autobiographical beliefs
}

\author{
Giuliana Mazzoni \\ University of Plymouth, Plymouth, England
}

\begin{abstract}
This study tested the hypothesis that the search for information pertinent to answering the question "Did event $x$ happen to you?" is preceded by a preliminary plausibility assessment, the outcome of which affects the amount of effort invested in the search. Undergraduate students were asked to assess the plausibility of six events and subsequently to rate their belief that each event had happened to them before the age of 6 . Unknown to them, response times (RTs) for answering the belief questions were also recorded. RTs for making belief judgments were more highly correlated with plausibility than with belief, and were significantly associated with plausibility even when belief ratings were controlled. As predicted, RTs were very short when the event was deemed highly implausible and increased sharply if the event was deemed at least somewhat plausible; significant but less pronounced increases in RTs followed as plausibility increased further.
\end{abstract}

How certain are you that you got lost in a mall or that you were harassed by a bully when you were 3 or younger? Did you break a window with your hand? Did a nurse remove a small piece of skin from your small finger when you were 6 or younger? Did you go for a hot air balloon ride when you were 6 or younger? These are some of the questions asked in studies on the creation of false autobiographical beliefs and memories (e.g., Garry, Manning, Loftus, \& Sherman, 1996; Loftus \& Pickrell, 1995; Mazzoni, Loftus, Seitz, \& Lynn, 1999; Mazzoni \& Memon, 2003; Wade, Garry, Read, \& Lindsay, 2002). These studies have shown that a variety of procedures (e.g., imagination, relatives' reports, dream interpretation, and doctored photographs) produce reliable increases in confidence about the occurrence of specific target autobiographical events, although in most cases the events had not in fact happened.

Studies have shown that event plausibility can moderate the effect of these procedures on memory (Pezdek, Finger, \& Hodge, 1997; Pezdek \& Hodge, 1999) and that increasing the perceived plausibility of a relatively implausible event (e.g., witnessing a demonic possession) can increase the belief that it has happened (Mazzoni, Loftus, \& Kirsch, 2001; Mazzoni \& Vannucci, 1999; Pezdek, Blandon-Gitlin, Lam, Hart, \& Schooler, in press; Scoboria, Mazzoni, Kirsch, \& Jimenez, in press). None of these studies, however, have assessed the cognitive processes underlying the relationship between these variables.

The study reported here was designed to examine the basic underlying mechanisms that might link event plausibility with autobiographical beliefs, and thereby shed light on the process by which plausibility affects beliefs about the occurrence of autobiographical events. The working hypothesis for this study stems from models proposed by Pezdek et al. (1997), Mazzoni et al. (2001), and Mazzoni and Kirsch (2002), in which both true and false autobiographical beliefs and memories result from a combination of memory search and decisional processes, similar to the model proposed by Koriat and Goldsmith (1996) for predicting response output. Pezdek et al. (1997) hypothesized that the process by which false autobiographical memories are formed begins with the development of a false autobiographical belief, which, in turn, is dependent on the plausibility of the event. Mazzoni et al. (2001) proposed a three-step model in which the evaluation of event plausibility is the first step in the development of false memories. Mazzoni and Kirsch (2002) then extended this earlier model to account for true as well as false autobiographical beliefs. The expanded model proposed that when the question "Did event $x$ happen to you?" is posed, it can trigger a search in knowledge and memory for information pertinent to answering the question. However, this search is subordinate to a preliminary decisional process in which the plausibility of the event is assessed in order to decide the degree to which a search is worthwhile (see also Pezdek et al., in press).

Although they are correlated, plausibility and belief are distinct constructs (Scoboria, Mazzoni, Kirsch, \& Relyea, 2004). An autobiographical belief is a judgment that an event has occurred (Ceci, 1995; Johnson \& Raye, 2000; Lampinen, Neuschatz, \& Payne, 1998; Mazzoni, Lombardo, Malvagia, \& Loftus, 1999). Mazzoni and Kirsch

G. Mazzoni, g.mazzoni@hull.ac.uk 
(2002) specified that such judgments apply to events that are not remembered as well as to those that are (see also Smeets, Merckelbach, Horselenberg, \& Jelicic, 2005). For example, people generally believe that they were born and that this occurred in a specific location on a specific date, even though they cannot remember the event. In contrast to belief, plausibility refers to the judgment that something might have reasonably happened, whether in fact it did or not. For example, most people judge almost choking on an small object when a child to be a highly plausible event, even if they do not believe that it in fact happened to them (Scoboria et al., 2004). Plausibility thus refers to the potential occurrence of an event (it could have happened), whereas belief refers to its actual occurrence (it did happen). See Scoboria et al. (2004) for a more detailed explanation of plausibility and its conceptual and empirical distinction from belief.

For events that are deemed completely implausible, searching memory or autobiographical knowledge would represent a worthless expenditure of cognitive resources, and therefore no search is undertaken. Search is worthwhile, however, for events that are deemed plausible. If an event is generally and personally plausible, then it might have happened, and if it did happen, some knowledge and/or memories relating to it could be found. Therefore, a search is undertaken for pertinent information. The more plausible the event, the more time and effort should be expended on this search. Thus, the hypothesis of this study is that the judgment that an event is at least somewhat plausible should produce a substantial increase in response latencies for answering the question "Did this event occur?" and that further increments in plausibility should result in more modest increases in response time (RT).

This hypothesis bears some similarity to hypotheses about the amount of time people take in giving "don't know" responses to questions (Gentner \& Collins, 1981; Glucksberg \& McCloskey, 1981; Klin, Guzmán, \& Levine, 1997; Koriat \& Lieblich, 1977). These studies have found that very fast responses are obtained when no relevant information is present in memory, whereas the provision of information slows down RTs, even if the information is irrelevant and uninformative. These results have been explained by postulating the presence of metacognitive processes that provide a fast preliminary evaluation of the stimulus or of the content of memory. Whether a further search in memory or other cognitive processes are activated depends on the output of these fast preliminary monitoring processes (see also Metcalfe, 1993). In a similar vein, it has been shown that preliminary plausibility judgments may precede slower memory retrieval in sentence verification tasks (Reder, 1982). The present study tested the hypothesis that in autobiographical memory tasks, monitoring the plausibility of an event constitutes a similar preliminary screening that allows a parsimonious and efficient use of cognitive resources.

The present study is the first time in which a behavioral measure has been used in examining the relationship between plausibility and autobiographical beliefs. Previous studies examining the relationship between plausibility and autobiographical belief have been limited to self-report measures, which are susceptible to various artifactual influences (e.g., compliance with perceived demand characteristics of the experimental situation). Surreptitiously assessed RTs are less susceptible to these influences.

In the present study, we measured the latencies of responses to the question "How likely is it that this event happened to you before the age of 6?" The prediction was that this measure of processing time would be significantly associated with the self-reported plausibility of the event, even when belief in its occurrence was held constant. One might expect RTs for making a decision to be more highly associated with the decision itself than with some other variable. This study makes the exact opposite prediction: It tests the hypothesis that the time required to decide whether an event has happened is more closely related to the perceived plausibility of the event than to the decision itself. In other words, plausibility ratings should be better than the belief ratings themselves in predicting the RTs for the belief ratings. In addition, because a determination that an event is implausible should preclude the initiation of a memory search, it was predicted that RTs would be very short when the event was deemed highly implausible, would increase sharply if the event was deemed at least somewhat plausible, and would increase to significant but less pronounced degrees as plausibility increased further.

An additional element worth emphasizing is that the prediction of an association between plausibility and RT should hold regardless of the decision that is made about the occurrence of the event. In other words, RTs should increase with increasing perceived plausibility, even when insufficient corroborating information is then found in memory, and thus the decision is that the event did not happen.

\section{METHOD}

\section{Participants}

Totals of 63 female and 27 male undergraduate education students in an introductory course in psychology at the University of Calabria (Italy) during the 1998-1999 academic year volunteered to take part in the study. Their ages ranged from 19 to 25 years old ( $M=20.6$ years). All students were born and raised in Calabria and came from diverse social and economic backgrounds.

\section{Materials}

Six events were selected that varied in probability of occurrence. One of the six events, "witnessing a demonic possession," was chosen as the primary event for statistical analyses because of the wide range in plausibility ratings obtained for this event in a previous study with students at the same university (Mazzoni et al., 2001). The remaining five events were taken from a Life Events Inventory (LEI) that had been used in previous studies (e.g., Mazzoni, Loftus, et al., 1999); all of these events had consistently been rated as more plausible than witnessing demonic possession. These events were "got sick while at school," "got lost in a public place for more than 1 hour," "almost choked," "won a toy at a fair," and "fell off a tricycle and received stitches." These five relatively plausible events were selected mainly as fillers, to dilute the focus on the less plausible demonic possession event. Nevertheless, their inclusion permitted additional evaluation of the hypothesized relation.

\section{Design and Procedure}

The study employed a within-subjects design with three variables: plausibility ratings, ratings of likelihood of occurrence (beliefs), and RTs for the belief ratings. Participants took part in the study indi- 
vidually. The six events were presented on a computer screen one at a time, in random orders that were different across participants but constant within participants across two presentations. For the first presentation, participants were asked to rate the personal plausibility of each event on a 4-point scale from 1 (highly implausible) to 4 (highly plausible) by responding to the question "How plausible is it that each of the following events could have occurred to a person like you before the age of 6 ?" During the second presentation, which occurred after the whole list had been presented for plausibility ratings, participants were asked to rate their belief that each event had actually happened to them by responding to the question "How certain are you that the following events happened to you before the age of 6?" These second ratings could range from 1 (I am certain it did not happen) to 8 (I am certain it did happen). Ratings were given by pressing the keys on the separate number keypad of the computer. To minimize differences in time due to search for the appropriate key on the keyboard, participants were given extensive practice in using the number keypad before the six items were presented. Plausibility and belief ratings, as well as the RT associated with each belief rating, were recorded by the computer. Participants were not informed that RTs were of interest or that they were being recorded.

\section{RESULTS}

Descriptive statistics for plausibility, belief, and response latency for providing belief ratings are reported in Table 1 for each of the six events. As anticipated, the range of plausibility ratings for all events except witnessing a demonic possession was truncated, in that there were no ratings of 1 (highly implausible) for any of those events by any of the participants. In contrast, demonic possession ratings covered the full range of possible plausibility ratings: Twenty-two participants rated this event as highly implausible, 27 rated it relatively implausible, 24 rated it relatively plausible, and 17 rated it highly plausible. A distribution of this sort was expected on the bases of prior research (Mazzoni et al., 2001) and knowledge of the cultural context of the population from which the sample was drawn. Because of the differences in the distributions of plausibility scores between the demonic possession event and the others, statistics involving the five plausible events should be seen as very conservative, and those for the possession event can be interpreted as more accurately reflecting relations between plausibility and other variables.

Differences between the events were analyzed with repeated measures ANOVAs followed by post hoc pairwise comparisons with Bonferroni corrections for multiple comparisons $(\alpha=.05)$. These analyses revealed significant effects of all three variables [plausibility, $F(5,445)=6.71$, $p<.001, M S_{\mathrm{e}}=0.63, \eta^{2}=.07$; belief, $F(5,445)=15.50$, $p<.001, M S_{\mathrm{e}}=4.85, \eta^{2}=.15 ; \mathrm{RT}, F(5,445)=16.97, p<$ $\left..001, M S_{\mathrm{e}}=29,208.12, \eta^{2}=.16\right]$. Post hoc comparisons indicated that witnessing a demonic possession was less plausible and produced quicker RTs than the other five events, which did not differ among themselves. Belief ratings for witnessing a possession, almost choking, and falling off a tricycle did not differ significantly but were significantly lower that belief ratings assigned to the remaining three events (winning a toy, getting lost, and getting sick), which also did not differ among themselves.

Pearson product-moment correlations (displayed in Table 2) were calculated to assess the relations between
Table 1

Mean Plausibility Ratings, Belief Ratings, and Response Times (RTs, in Milliseconds) for the Six Events

\begin{tabular}{|c|c|c|c|c|c|c|}
\hline \multirow[b]{2}{*}{ Event } & \multicolumn{2}{|c|}{ Plausibility } & \multicolumn{2}{|c|}{ Belief } & \multicolumn{2}{|c|}{ Belief RT } \\
\hline & $M$ & $S D$ & $M$ & $S D$ & $M$ & $S D$ \\
\hline Possession & 2.40 & 1.06 & 1.67 & 1.46 & 645 & 286 \\
\hline Toy & 3.02 & 0.75 & 3.47 & 2.89 & 809 & 125 \\
\hline Sick & 2.84 & 0.85 & 3.61 & 2.79 & 837 & 153 \\
\hline Choke & 2.81 & 0.69 & 1.81 & 1.85 & 832 & 132 \\
\hline Lost & 2.93 & 0.73 & 3.56 & 2.54 & 834 & 142 \\
\hline Tricycle & 2.89 & 0.80 & 2.28 & 1.90 & 815 & 155 \\
\hline
\end{tabular}

Note-Plausibility was rated on a scale of 1-4; belief was rated on a scale of $1-8$.

plausibility ratings, autobiographical belief ratings, and belief response latencies. Plausibility and autobiographical belief response latency were significantly correlated for each of the six events (mean $r=.63$ ), as were plausibility and belief (mean $r=.57$ ), and belief and belief response latency (mean $r=.39$ ).

The hypothesis about the relationship between plausibility and RTs for belief-in-occurrence ratings predicts that the RTs should be more strongly correlated with plausibility than with the belief ratings themselves. Two procedures were used to test this hypothesis. First, tests of differences between dependent correlations revealed that these differences were significant for four of the six events, including the primary event [possessed, $t(87)=$ $4.21, p<.001$; toy, $t(87)=2.61, p<.05$; sick, $t(87)=$ $1.99, p<.05$; tricycle, $t(87)=1.99, p<.05$ ], despite the fact that the RTs were those for making belief rather than plausibility ratings. Second, belief response latency was regressed on both plausibility and belief. The results of the regression analyses for each of the six events are presented in Table 3. In each case, with belief ratings controlled, the association between plausibility and latency remained significant (mean $\beta=.61$ ), whereas with plausibility controlled, the association between belief and latency was not significant for any of the events, confirming the hypothesis that response latencies for beliefs are related to plausibility, independently of their relationship with belief.

Because of the relatively high correlations between plausibility and belief, the regression coefficients reported for the whole sample in Table 3 might be unstable. As a first step in assessing multicollinearity within this data

Table 2

Correlations Between Plausibility Ratings, Response Times (RTs), and Belief-in-Occurrence Ratings for Each of the Six Events

\begin{tabular}{lccl}
\hline \multicolumn{1}{c}{ Event } & $\begin{array}{c}\text { Plausibility } \\
\times \mathrm{RT}\end{array}$ & $\begin{array}{c}\text { Plausibility } \\
\times \text { Belief }\end{array}$ & $\begin{array}{c}\text { Belief } \\
\times \mathrm{RT}\end{array}$ \\
\hline Possession & $.77^{* *}$ & $.33^{*}$ & $.29^{*}$ \\
Toy & $.66^{* *}$ & $.55^{* *}$ & $.37^{*}$ \\
Sick & $.55^{* *}$ & $.82^{* *}$ & $.40^{*}$ \\
Choke & $.56^{* *}$ & $.42^{* *}$ & $.37^{*}$ \\
Lost & $.64^{* *}$ & $.78^{* *}$ & $.55^{* *}$ \\
Tricycle & $.59^{* *}$ & $.55^{* *}$ & $.36^{*}$ \\
\hline
\end{tabular}

${ }^{*} p<.01 . \quad{ }^{* *} p<.001$. 
Table 3

Regression Analyses With Response Latencies Regressed on Plausibility and Belief Ratings for Each of the Six Events

\begin{tabular}{|c|c|c|c|c|c|}
\hline \multirow[b]{2}{*}{ Event } & \multicolumn{2}{|c|}{ Plausibility } & \multicolumn{2}{|c|}{ Belief } & \multirow[b]{2}{*}{ VIF } \\
\hline & $B$ & $S E$ & $B$ & $S E$ & \\
\hline Possession & $203.28^{*}$ & 19.61 & 9.40 & 14.20 & 1.12 \\
\hline Toy & $108.22^{*}$ & 16.14 & 0.80 & 4.18 & 1.43 \\
\hline Sick & $121.65^{*}$ & 27.95 & -8.48 & 8.49 & 3.00 \\
\hline Choke & $94.45^{*}$ & 18.74 & 11.43 & 6.95 & 1.22 \\
\hline Lost & $101.79^{*}$ & 25.66 & 8.10 & 7.39 & 2.58 \\
\hline Tricycle & $109.69^{*}$ & 19.96 & 4.59 & 8.39 & 1.42 \\
\hline
\end{tabular}

set, variance inflation factor (VIF) values were calculated and are reported in Table 3. Although the resulting values were well below the cutoffs most commonly recommended, some regard those cutoffs as too liberal (Cohen, Cohen, West, \& Aiken, 2003). Therefore, the sample was randomly divided into two subsets (A and B), and RTs for the primary dependent variable (demonic possession) were regressed on plausibility and belief using the data from Subset A only. The parameters of the regression equation obtained for Subset A were then used to calculate predicted RTs for Subset B. The differences between the observed and predicted RTs for Subset B were then calculated, and the square root of the sum of their squared values was then divided by the number of participants. This resulted in a mean difference between predicted and observed RTs of $32.70 \mathrm{msec}$. The standard deviation of the RTs for the possession event across the whole sample was $286 \mathrm{msec}$. Thus, the difference between the predicted and observed RTs was only $0.1 S D$ s. The correlation between the predicted and observed RTs was .75 $(p<.001)$. These data indicate that the results of the regression analyses are reasonably reliable.

Finally, the mean RT was calculated for each plausibility rating of each event, and these are shown in Figure 1. These data show the predicted large increase in RTs between highly implausible and relatively implausible ratings, fol- lowed by smaller increases as a function of further increases in plausibility rating. They also show remarkable consistency across events in RTs as a function of plausibility.

\section{DISCUSSION}

The study reported here tested the hypothesis that time spent searching in memory when deciding whether an event has occurred is strongly related to the perceived personal plausibility of the event. If an event is highly implausible, there is no need to search in memory, and the answer should be derived directly from the decision about plausibility. When an event is not highly implausible, the time to say whether it actually happened should be proportional to the perceived level of plausibility, so that the greater the plausibility of an event, the more time should be used to come up with a response about its occurrence. This should be true for all events, even when the resulting belief is that the event did not happen. In other words, when an event is considered plausible, people should spend more time searching for corroborating evidence in autobiographical knowledge/memory, but this process does not guarantee that the evidence found will be sufficient for the person to conclude that the event happened. The outcome could be either positive ("yes, it happened") or negative ("no, it did not happen").

As hypothesized, response latencies for responding to a question about one's belief that an event occurred were predicted by the perceived plausibility of the event. This association was significant even when belief was controlled, whereas the association between belief and response latency was not significant when plausibility was controlled. As predicted, RTs were very short $(M=$ $230 \mathrm{msec}, S D=102)$ when an event was considered highly implausible, but rose considerably once the event was judged to have passed that threshold $(M=701 \mathrm{msec}$, $S D=104)$. Thereafter, the increases in RTs associated with increasing plausibility were modest (relatively plau-

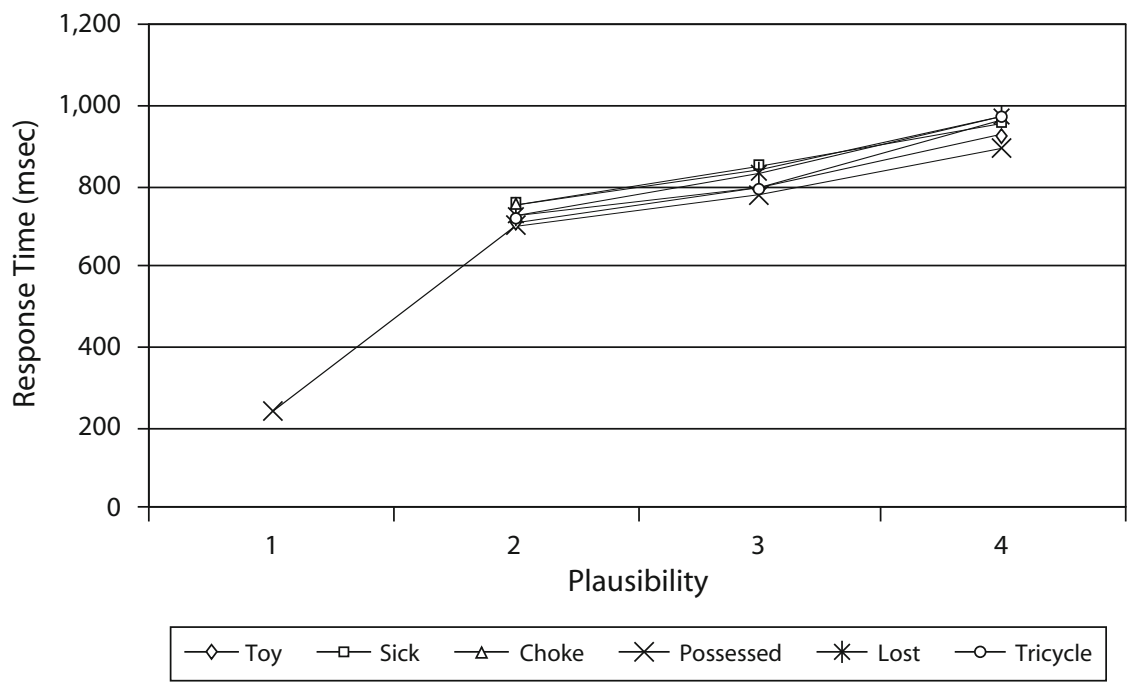

Figure 1. Response time as a function of plausibility for each of the six events. 
sible, $M=777 \mathrm{msec}, S D=209$; highly plausible, $M=$ $898, S D=187)$. These findings seem particularly striking in view of the fact that the response latencies measured were for belief and not for plausibility.

In summary, the data presented here support the hypothesis that testing item plausibility represents the first step when deciding whether an event occurred, and they indicate that the level of plausibility determines the amount of time spent searching for evidence supporting the occurrence of an event. However, the mechanism appears to be even more specific. If an event is considered completely implausible, the decision that it did not occur seems to be reached very quickly, presumably because there is no point searching for additional information about whether the event happened. Instead, the person concludes that because it is implausible, it cannot have happened. Conversely, if the event is plausible, additional information is needed to determine whether it has happened, and the more plausible the event, the more time the person will spend searching for relevant information.

These data suggest that the relationship observed in previous work of plausibility to autobiographical belief and memory (Mazzoni et al, 2001; Pezdek et al., 1997; Pezdek \& Hodge, 1999; Scoboria et al., 2004) is the outcome of a metacognitive process that could be termed (borrowing Schacter, Israel, \& Racine's, 1999, terminology) a "plausibility heuristic"; this process is a shortcut that restrains the system from using cognitive resources that would in most cases be wasted. More detailed delineation of the functioning of this plausibility heuristic and its relationship with subsequent memory operations is an important topic for further studies.

\section{AUTHOR NOTE}

The author thanks Irving Kirsch for his helpful suggestions in preparing the final version of this article. Correspondence relating to the article may be sent to G. Mazzoni, Department of Psychology, University of Hull, Cottingham Road, Hull HU6 7RX, U.K. (e-mail: g.mazzoni@hull.ac.uk).

\section{REFERENCES}

CECI, S. J. (1995). False beliefs: Some developmental and clinical considerations. In D. L. Schacter (Ed.), Memory distortions: How minds, brains, and societies reconstruct the past (pp. 91-125). Cambridge, MA: Harvard University Press.

Cohen, J., Cohen, P., West, S. G., \& Aiken, L. S. (2003). Applied multiple regression/correlation analysis for the behavioral sciences (3rd ed.). Mahwah, NJ: Erlbaum.

Garry, M., Manning, C. G., Loftus, E. F., \& Sherman, S. J. (1996). Imagination inflation: Imagining a childhood event inflates confidence that it occurred. Psychonomic Bulletin \& Review, 3, 208-214.

Gentner, D., \& Collins, A. (1981). Studies of inference from lack of knowledge. Memory \& Cognition, 9, 434-443.

GluCKSBerg, S., \& MCCloskey, M. (1981). Decisions about ignorance: Knowing that you don't know. Journal of Experimental Psychology: Human Learning \& Memory, 7, 311-325.

Johnson, M. K., \& RaYe, C. L. (2000). Cognitive and brain mechanisms of false memories and beliefs. In D. L. Schacter \& E. Scarry (Eds.), Memory, brain, and belief (pp. 35-86). Cambridge, MA: Harvard University Press.

Kuin, C. M., Guzmán, A. E., \& Levine, W. H. (1997). Knowing that you don't know: Metamemory and discourse processing. Journal of Experimental Psychology: Learning, Memory, \& Cognition, 23, 1378-1393.

KoRIAT, A., \& GoldSMith, M. (1996). Monitoring and control processes in the strategic regulation of memory accuracy. Psychological Review, 103, 490-517.

Koriat, A., \& Lieblich, I. (1977). A study of memory pointers. Acta Psychologica, 41, 151-164.

Lampinen, J. M., Neuschatz, J. S., \& Payne, D. G. (1998). Memory illusions and consciousness: Examining the phenomenology of true and false memories. Current Psychology: Developmental, Learning, Personality, Social, 16, 181-224.

Loftus, E. F., \& Pickrell, J. E. (1995). The formation of false memories. Psychiatric Annals, 25, 720-725.

Mazzoni, G. [A. L.], \& KIRSCH, I. (2002). Autobiographical memories and beliefs: A preliminary metacognitive model. In T. J. Perfect \& B. L. Schwartz (Eds.), Applied metacognition (pp. 121-145). Cambridge: Cambridge University Press.

Mazzoni, G. A. L., Loftus, E. F., \& Kirsch, I. (2001). Changing beliefs about implausible autobiographical events: A little plausibility goes a long way. Journal of Experimental Psychology: Applied, 7, 51-59.

Mazzoni, G. A. L., Loftus, E. F., Seitz, A., \& Lynn, S. J. (1999). Changing beliefs and memories through dream interpretation. Applied Cognitive Psychology, 13, 125-144.

Mazzoni, G. A. L., Lombardo, P., Malvagia, S., \& Loftus, E. F. (1999). Dream interpretation and false beliefs. Professional Psychology: Research \& Practice, 30, 45-50.

MaZzoni, G. [A. L.], \& Memon, A. (2003). Imagination can create false autobiographical memories. Psychological Science, 14, 186-188.

Mazzoni, G. [A. L.], \& Vannucci, M. (1999, July). The provision of new information can change beliefs and memories about autobiographical events. Paper presented at the meeting of the Society for Applied Research in Memory and Cognition, Boulder, CO.

MetCALFE, J. (1993). Novelty monitoring, metacognition, and control in a composite holographic associative recall model: Implications for Korsakoff amnesia. Psychological Review, 100, 3-22.

Pezdek, K., Blandon-Gitlin, I., Lam, S., Hart, R., \& Schooler, J. W. (in press). Is knowing believing? The role of event plausibility and background knowledge in planting false beliefs about the personal past. Memory \& Cognition.

Pezdek, K., Finger, K., \& Hodge, D. (1997). Planting false childhood memories: The role of event plausibility. Psychological Science, $\mathbf{8}$, 437-441.

Pezdek, K., \& Hodge, D. (1999). Planting false childhood memories in children: The role of event plausibility. Child Development, $\mathbf{7 0}$, 887-895.

Reder, L. M. (1982). Plausibility judgments versus fact retrieval: Alternative strategies for sentence verification. Psychological Review, 89, 250-280.

Schacter, D. L., Israel, L., \& Racine, C. (1999). Suppressing false recognition in younger and older adults: The distinctiveness heuristic. Journal of Memory \& Language, 40, 1-24.

Scoboria, A., Mazzoni, G., Kirsch, I., \& Jimenez, S. (in press). The effects of prevalence and script information on plausibility, belief, and memory of autobiographical events. Applied Cognitive Psychology.

Scoboria, A., Mazzoni, G., Kirsch, I., \& Relyea, M. (2004). Plausibility and belief in autobiographical memory. Applied Cognitive Psychology, 18, 791-807.

Smeets, T., Merckelbach, H., Horselenberg, R., \& Jelicic, M. (2005). Trying to recollect past events: Confidence, beliefs, and memories. Clinical Psychology Review, 25, 917-934.

Wade, K. A., Garry, M., Read, J. D., \& Lindsay, D. S. (2002). A picture is worth a thousand lies: Using false photographs to create false childhood memories. Psychonomic Bulletin \& Review, 9, 597-603.

(Manuscript received February 14, 2006; revision accepted for publication April 28, 2006.) 